\title{
Sanitation Dilemmas and Africa's Urban Futures: Foregrounding Environmental Public Health in Contemporary Urban Planning
}

\author{
Bob O. Manteaw \\ Center for Climate Change and Sustainability Studies, \\ University of Ghana, Legon, Ghana
}

DOI: https://doi.org/ 10.36941/ajis-2020-0096

Abstract

Africa is rising, so goes the current narrative on Africa's growth and development prospects. While most of these narratives are in direct reference to economic indicators and existing potentials for Africa's sustainable development, there is no doubt that the rapidly urbanizing landscapes of Africa, characterized by sprawling cities, high-rise buildings, and flashy city lights represent an urban revolution in most of Africa's cities. Beneath the glow of flashy city lights lies a dark and gloomy contrast: inner city slums, sanitation dilemmas and environmental public health challenges which converge to pose significant challenges to Africa's broader sustainable development aspirations. This paper foregrounds urban sanitation challenges and public health imperatives from a contemporary urban planning perspective. The paper argues that urban planning and public health have shared a close historical relationship both in thinking and practice; however, recent developments in urbanization processes have seen the two professions drift apart. The paper further asserts that human habitat considerations from the perspective of urban planning in Ghana, in particular, treat issues of sanitation management and public health and safety issues as after-thoughts and are excluded in initial planning processes. While the paper acknowledges the influence of increased population growth and the reality of climate change in current urbanization processes, the paper advocates for new approaches that make cities and other urbanizing communities resilient.

Keywords: Urban Planning, Public Health, Sanitation Governance, Urbanization, Sustainable Development

\section{Introduction}

Africa is rising, so goes the current narrative on Africa's growth and development prospects (Brooks, 2018; McKenzie, 2016; Hofmeyr, 2013). While most of these narratives are in direct reference to current and potential future economic growth indicators, there is no doubt that the rapidly urbanizing landscapes of Africa, characterized by population growth, sprawling cities, high-rise buildings, and flashy city lights represent an unfolding urban evolution in most of Africa's cities (Barros, Chivangue \& Samagaio 2014; Taylor, 2016; UNEP, 2012; UN-Habitat, 2014). Beneath the glow of the flashy city lights, however, lie a dark and gloomy contrast: inner city slums, sanitation, hygiene, water, and public health challenges which, rather ominously, converge to provide an audibly muted counter-narrative to the Africa rising narratives.

While Africa rises, as per the narrative, and as cities continue to provide the requisite anchorage for growth and development (Bodini, Bondavalli \& Allesina, 2012), it is also a fact that most of Africa's cities and urbanized communities face sanitation and public health dilemmas steeped in a paradox of growth and insalubrious decay. Surge urbanization, characterized by rapid shifts in population flows 
from rural to urban settings, has become a key feature in the development of unplanned human settlements in urban societies across Africa with attendant sanitation and public health challenges (Cobbinah Poku-Boansi \& Peprah.2017). The pervasiveness of filth and insanitary conditions in urban Africa's big cities is what (Njoh, 2012) describes as manifold manifestations of unhygienic and insalubrious conditions that characterize human settlements across Africa's many cities. The situation is common particularly in Sub-Saharan Africa (SSA) where unsightly spectacles of filth, of all forms, have become worrying concerns in local communities with associated, sanitation, hygiene and public health ramifications.

In this paper, I foreground urbanization and public health challenges in Africa with a particular focus on Ghana. Using a combination of historical and theoretical analysis, the paper locates the discussion within the broader sustainable development agenda to explore the linkages between urbanization and the quest for sustainable development in Africa (Roders, 2013). In particular, the link between urban planning and public health is highlighted within Africa's sustainable development aspirations. The paper takes the view that contemporary urban planning and human habitat considerations in most of Sub-Saharan Africa treat issues of sanitation management and public health as afterthoughts and are, for the most part, excluded in initial planning processes.

Furthermore, it is the contention of the paper that urban planning in Africa, as a specialist field of practice, has veered off from a historically long-standing relationship with public health (Njoh, 2012; Obeng-Odoom, 2012). This shift, the paper argues, has come at a significant cost to contemporary urbanization and sustainable development processes. Focusing primarily on Ghana, but with references to other African cities, the discussion will focus on current sanitation issues in cities and urban communities and how and why they threaten both the future of cities and the quest for sustainable development. First, I examine the implications of urbanization on Africa's sustainable development prospects by exploring underlying challenges and potential opportunities. This is followed by a discussion on the growing sanitation challenges in cities and urban communities in Africa. The public health dimensions of sanitation (mis)management in cities will follow to critically assess the links between urban planning, sanitation management and public health in Africa's cities.

\section{Urbanization and Sustainable Development in Africa}

The urban age is unfolding in many places around the world with more than half of the world's population living in cities and other fast-urbanizing communities (UN-Habitat. (2016)). Even though the continent of Africa is largely rural, it remains one of the fastest urbanizing regions in the world with populations expected to more than triple in the next forty years (Cobbinah, 2015). Current projections suggest population growth rate in Africa's urban regions could swell from 395 million in 2010 to around 1.339billion in 2050 (UN-DESA, 2014; UN-Habitat, 2014). As unusual as such growth rates are, they have become a defining character of Africa's fast-urbanizing processes and one that undoubtedly has mixed implications for the continent's sustainable development aspirations.

Urbanization, in its simplest explanation, is linked to the expansion of urban areas due to increases in population movements largely from rural areas to urban areas and as a result of social and economic changes which serve as attractions to migrants (Peter \& Yang, 2019). Its evolution and manifestation in many societies represent, perhaps, the most important socio-ecological transformation in the history of civilization and has proved critical to economic growth and expansion processes in most countries (Henderson, 2005). Such expansions do not only attract migrants from rural areas into cities, but also brings about major and irreversible changes that affect people, environment, production and consumption processes (Cobbinah, Erdiaw-Kwasie \& Amoateng, 2015). These changes manifest in various ways and are embodied in the diversity of social processes and also in the ways in which people interact with goods and services in their different places. The eventual impacts of the different social processes are diverse; however, they ultimately shape the outcomes of urbanization to be either negative or positive.

The United Nations Agency for Human Habitats, UN HABITAT, has predicted that over 90\% of 
human populations will be living in large cities around the world but more so in developing regions such as Africa (UN-Habitat, 2014; UN-Habitat, 2016). This prediction seems to be playing out forcefully across Africa where unprecedented urbanization processes continue to bring into sharp focus the rather complex relationships that exists between urbanization and sustainable development. The spate and speed of urbanization across Africa is seen by many to be on an unusually fast trajectory and with considerable implications for Africa's sustainable development aspirations (Peter \& Yang, 2019). The potential for urbanization to enhance sustainable development processes has never been in doubt as many continue to tout its potential and capability to transform people and places for the better (Shen et al., 2017). However, it is also a recognized fact that uncontrolled and unplanned urbanization, the like of which has become a common feature across Africa, could pose significant threats to sustainable development.

As the urbanization phenomenon intensifies in all major cities across Africa, it has also become apparent that city authorities and urban planners have been overwhelmed by associated challenges and have not been able to cope with management requirements. The result, as is verifiable in most of Africa's fast-urbanizing communities, is the emergence of chaotic and disorganized situations which, almost invariably, have underlying social, economic, environmental, and health dimensions. Slums, sprawls, vehicular and human congestions, waste and sanitation mismanagement challenges, disease out breaks, crimes and many more characterize Africa's urban revolution (Cobninah, Poku-Boansi \& Preparah, 2017) It is a chaotic revolution which is also reflective of the haphazard nature of urbanization processes and the non-adherence to urban planning principles or procedures.

\subsection{Cities as Engines for Growth}

The current wave of urbanization sweeping across Africa puts the continent at the crossroads as most cities have to walk the tight lines of taking advantage of associated benefits, as well as finding responses to emerging challenges. This is a quandary which is suggestive of the potential benefits of urbanization for social and economic development and also the threatening risks which are invariably counter-productive to the sustainability of urban futures. This, indeed, is the dilemma that many of Africa's cities face as they make the unchartered transition into a fast-paced urbanization culture (Aliyu \& Amadu, 2017; Kessides, 1997; Lall, Henderson \& Venables, 2017).

Current urbanization processes are stylized and reflective of what I describe as urban evolution in some if not most of Africa's large cities. Lagos, Nairobi, Dare Salem, Addis Ababa, Accra, Cape Town, Johannesburg, Kampala and many others are some of Africa's largest cities currently leading the urban revolution. These cities have become engines for growth and hubs for development for their respective countries as they continue to open up opportunities for those who migrate into cities. They also host most of Africa's thriving industries and as a result have become the face of the Africa rising narratives. The reality, however, remains that if indeed Africa's fast-growing cities are hubs for innovation or engines for economic growth, then the numbers and diversity of people living in these cities are the lubricants for the full functionality of the engine. People, and in this regard populations, are at the very core of current economic and socio-ecological transformation processes happing in Africa's cities and are also those who enjoy the immediate benefits of urbanization (Saunders, 2011).

Against the background of current economic and social transformation processes going on in cities across Africa, it will be an unexaggerated conclusion to say that in spite of all the perceivable negative attributes of urbanization there are also significant advantages that urbanization processes present. From employment opportunities, education, transportation, markets, technological innovations, welfare, social organization to networked institutions, cities are uniquely structured and well-positioned to ensure innovation and efficiency in both the production and distribution of goods and services and to create efficient synergies between the economy, environment and society (Robinson \& Swilling, 2012; UNEP, 2012).

In many ways, therefore, the different opportunities associated with processes of urbanization validate the widely-held view that urbanization is a byproduct of economic development and that 
there is overlap between urbanization and sustainable development (Cobbinah, Erdiaw-Kwasie, \& Amoateng, 2015). This overlap, as observed, is deeply rooted in economic development processes which, in their diversity, serve as catalyst for economic and socio-ecological transformations. Thus, as much as cities remain engines for growth and hubs for economic transformation, the efficiencies of such transformations are largely dependent on the extent to which urbanization processes are intentionally planned.

This is to say that well-organized processes and forward-looking approaches are the bedrocks for human and institutional capabilities building to create resilient cities for sustainable development (Jha, Miner \& Stanton-Geddes, 2013; Storper, 2013). Cities, undoubtedly, have the potential to transform socio-economic conditions and to reduce human vulnerabilities; however, this potential is not fully leveraged in most of current urbanization processes in Africa and largely because a good number of current urbanization processes are unplanned and uncontrolled. There are lots of cities and other urbanizing communities across Africa that have either developed or are developing without plans and much as they maintain their statuses as hubs for economic growth, the lack of planning and forward-looking approaches impede the efficient leveraging of associated benefits to support further growth and development.

Ghana's four largest cities: Accra, Kumasi, Takoradi and Tamale provide good examples of cities overwhelmed with population growth and a lack of planning (Adarkwa, 2012; Boamah, Gyimah, \& Nelson, 2012; Boamah, 2013; Cobbinah \& Darkwah, 2016). While urbanization processes continue in these cities, there is also ample evidence of how city dwellers are suffering from the consequences of poor urban planning and ineffective or inappropriate policies. This, again, is a common story across Africa and reflective of endemic political and policy failures in the planning and management of urban settlement and urban development concerns (Harrison, 2006). The result, as has become evident in most cities, is widespread urban poverty, overcrowding, slums, poor social services including health, waste and sanitation management. The lack of these services in urban communities has become major impediments to the full realization of the potential of cities, in particular, as hubs and enablers of growth and development.

These impediments along with other factors such as unregulated and chaotic urbanization processes threaten sustainable development processes and provide ample reason for caution when generalized assumptions are made about the positive influences of urbanization to sustainable development processes. It is from such a perspective that narratives of Africa rising should be given a thorough and careful scrutiny to establish what is actually gained and or lost in the process. Thus, if Africa is indeed rising and urbanization is at the forefront of such narratives, then there is need for a focused attention on the identified negative influences of urbanization and how they shape, or not, the African rising narratives.

\subsection{Urbanization as a Threat to Sustainable Development}

Urbanization everywhere may present considerable challenges and opportunities for countries and this is irrespective of the development status of a country (Yankson, \& Bertrand, 2012). In many instances, however, and more so in Africa's current situation, the prevalence of weak governance institutions and inadequate planning processes constrain the potential benefits to be derived from urbanization. Most benefits are impeded or neutralized by some underlying negative factors which, ultimately, threaten sustainable development processes (Hove, Ngwerume, \& Muchemwa, 2013). Ineffective service provision in urban communities and the chaotic manner in which urbanization processes unfold make it difficult for cities to fully leverage the advantages of urbanization.

Thus, while there are obvious benefits from urbanization, there is also no doubt that unplanned and uncontrolled urbanization sometime pose significant threats to any prospect of sustainable development (Hove, Ngwerume, \& Muchemwa, 2013). Growing populations and concentration of people in cities may be perceived as advantageous in the manner in which they serve diverse economic and social interests. However, these advantages are constrained by a lack of effective 
planning, insufficient resources, weak institutions, increased incidents of poverty, vulnerability, squalor, insecurity and environmental degradation (UN-Habitat, 2012; UNEP, 2013). These are defining traits of urbanization in Africa's cities; they are perceivable and verifiable in most cities and have a high propensity to disrupt sustainable development processes.

Just as urbanization continues to be touted as byproducts of economic expansion, poverty, squalor, marginalization and vulnerability, the type of which has become a common feature in contemporary urbanization processes across Africa, could also be seen as a function of unplanned and unregulated urbanization process. The pervasiveness of such situations across cities and in different countries somehow legitimizes the argument that there is a relationship between rapid, unplanned and uncoordinated urbanization processes and unsustainable development trends (UNHabitat, 2012; UNEP, 2013). So, while cities are currently unstoppable in their urbanization evolution, most of these processes lack guidance or plan and have locked cities up in chaotic and dysfunctional spatial arrangements characterized by ever-worsening socio-ecological conditions.

An efficient urban management system is a necessity to leverage the full benefits of urbanization for sustainable development (Keiner, 2004). This, however, will require conscious and intentional pathways carefully devised to take advantage of available opportunities associated with urbanization. These pathways should be characterized by the ability of authorities, and in this case, city governments and urban planners, to anticipate growth trends and to plan accordingly to meet the demands of the times (Cobbinah \& Erdiaw-Kwasie, 2016). This involves the prompt provision of essential goods and services for the maintenance of waste and sanitation management infrastructure and services to assure good public health. This, however, is not the situation in most of Africa's current urbanizing communities as most cities face what I describe as sanitation dilemma.

\section{Sanitation Dilemmas and Urban Futures in Africa}

Urbanization processes in Africa do not only present public health challenges, but are seen by many as being a public health challenge in and by themselves (Sclar et al., 2005). This is precisely because sanitation and public health challenges have become a predictable feature of most urbanizing processes across Africa. This predictability is explained by the fact that while population increases and economic growth fuel urban expansion, weaknesses in governance and poor planning with regard to waste and sanitation service provision have already shown ability to threaten public health. This remains the reality of most of Africa's cities and as they continue to grow with unprecedented intensity, both in sizes and populations, the inefficient management of waste and sanitation has emerged as a major urbanization challenge with attendant public health ramifications (Manteaw \& Boachie, 2019).

Most cities are overwhelmed by the pace of urbanization processes and are unable to cope with the needs and demands of such growth rates. The fast-paced growth in populations and in spatial expansion have severely affected the ability of city authorities to provide functional and efficient services such as sanitation and public health ( Hove, Ngwerume, \& Muchemwa, 2013). The situation, as I have already discussed, is common across Africa and it is one that Nojoh (2012) described as widespread and manifold spreading from Cairo to Cape Town and from Dakar to Mogadishu. It is what I describe as Africa's sanitation dilemmas.

It has become common in most Sub-Saharan African cities for any visitor to witness scenes of uncollected heaps of garbage, choked drains and littered streets (Njoh, 2012; Hardoy et al., 2006). This is certainly the case in Accra, Ghana, where unsightly spectacles of uncollected waste and insanitary conditions in many communities provide poignant insights into current urban sanitation and hygiene challenges across most of Africa. And, it is what I describe in this work as Africa's urban sanitation dilemmas, which gets even worse during periods of heavy precipitation when a mix of solid and liquid waste clash sometime very violently with surface running water to cause floods in local communities (Karley, 2009). These occurrences have become rampant and almost predictable annual events which bring disastrous consequences. 
The link between waste mismanagement and flooding has somehow become a normalized feature of urbanization, at least in Ghana, where large cities such as Accra and Kumasi endure frequent flooding and constant outbreaks of various forms of communicable diseases such as dysentery, diarrhea, typhoid etc. Some of these flooding instances have also resulted in loss of lives and property and it is largely because of the pervasive presence of indiscriminately disposed solid waste which end up choking drains and waterways to cause floods. Slum communities, as part of the urbanization experience, are usually the most vulnerable as they lack household and communal waste receptacles. This explains the frequent incidences of floods and associated disasters which, more often than not, come with socio-environmental traumas and mental health challenges that usually 264 go undiagnosed. As unfortunate as these are, they are realities associated with urbanization and the concerntration of people in spatially unplanned urban domains. They are not just an Accra or Ghana problem; they are Sub-Saharan African urban realities that play out differently in diverse countries and contexts.

The common underlying factor is that most of these fast-urbanizing communities have weak urban governance structures where planning processes are weak or non-existent. So, beneath these urban sanitation and public health realities, lie the bigger challenge: urban growth (mis)management and the critical issue of waste and sanitation management which, invariably, highlights systematic linkages among urban planning, waste management, sanitation and public health. These linkages are also indicative of underlying management requirements which are supposed to be integrative and well-coordinated to underscore how population growth trends, economic development, human settlements, waste and sanitation management work together to ensure well-being, public health and safety.

\section{Urban Planning and Public Health in Contemporary Africa}

Urban Planning, as Okpala (2009) describes is the "the process of programming the coordination of the direction, structure and pattern of the development, growth and management of urban settlements..." p.4). The goal is to ensure that all necessary land-use needs (including economic, social, environmental, institutional, cultural, recreational and leisure needs), for the different socioeconomic demographic in society are provided for in the planning process. Such planning processes are also to safeguard public health which has had historical operational and thinking relationship with urban planning then known as Town Planning (Courburn, 2004; Courburn, 2009; Njoh, 2007; Verbeek, 2014; Porter, 2005).

The histories between Public Health and Urban Planning are twinned and date back to the industrial revolution and even beyond when human settlement issues and sanitary conditions were central concerns of the industrial revolution and human settlement processes (Konteh, 2009; Njoh, 2009). Public health, Town Planning, and Civil Engineering as professions evolved together as a response to the harmful effects of rapid industrialization, migration and population growth challenges that had characterized the industrial revolution. Housing challenges and over-crowding in rapidly urbanizing communities saw frequent outbreaks of infectious diseases which necessitated the coming together of the three professions to work closely together (Duhl, Sanchez, \& World Health Organization, 1999; Melosi, 2000).

Built environment reformers of which the three professions belonged recognized that poor housing conditions, inadequate sanitation, ventilation, and dangerous working conditions associated with the industrialization processes contributed to outbreaks of dangerous infectious diseases such as cholera and typhoid. It became clear at this time that filth or insanitary conditions were outcomes of human settlement congestions and deplorable living conditions which created just the right environments for pathogens to thrive and to cause diseases (Corburn,2004). As these became more pervasive, critical social amenities were also scant: water and sanitation facilities were absent as human communities endured insalubrious conditions and frequent disease outbreaks. Early excitements about the industrial revolution became fraught with environmental public health 
challenges which subsequently prompted various theories and approaches about what caused diseases and how best to protect human health.

The task for ensuring good public health within the built environment then fell within the remit of public health and town planning authorities, as well as other allied professionals whose task it was to prevent such occurrences. This set-in motion a close working relationship between the two professions-Urban Planning and Public Health-which, Njoh (2012), has described as twinned. This early professional relationship thrived on the consequential challenges of the industrial revolution which were mainly human settlement and environmental health-related. They were sanitary and hygiene problems which brought urban planning and public health to work ever closer to explore collaborative solutions. The two professions blossomed as they worked together over time to ensure and assure public health and safety in the built environment. Njoh (2007) locates this professional relationship in history by noting that public health and town planning are consanguine relatives rooted in common ancestry in the sanitary movement of the mid-19 ${ }^{\text {th }}$ century.

This historical relationship between the two professions is not only significant by their twinned operational practices, but also in the ways in which similar notions of town planning and public health were imported into Africa during the colonial era (Home, 2013). Town planning was employed essentially as a zoning tool to protect the health and safety of colonial administrators during the colonial era. It therefore became a preventive mechanism against social disorder, chaotic situations, and disease outbreaks in most of the colonies across Africa. Such mechanisms were legitimized through legislation processes (Carmichael et al. 2019, Njoh, 2012). Indeed, Njoh (ibid), was particular about the fact that "public health elements featured prominently in town planning legislation..." (p.10). Unfortunately, this long-standing primacy of health is what seems to have been lost in contemporary urban planning processes across Africa.

\subsection{Beginning of the end of a Twinned Practice}

The enduring culture of disease prevention as a key aspect of built environment planning is what seems to be missing in current urban planning approaches in Africa as many countries and their fasturbanizing communities are witnessing what looks like an institutional separation of public health and urban planning (Corburn, 2004; Greenberg, Popper, West \& Krueckeberg, 1994; Verbeek, 2014). This separation, as has become common place in many of Africa's fast-urbanizing communities, has created a gap which, in many instances, has resulted in uncoordinated approaches to addressing the complexly interconnected challenges of urban development and public health. While public health in its contemporary form seems more focused on biomedical factors that explain disease behaviors within the built environment (Corburn, 2004), there is also enough evidence, at least from the observable display of filth and insanitary conditions on city streets and in communities across urban Africa, to suggest that such a focus has since been lost.

There seem to be a shift in attention from prevention and preventive zoning and planning practices to land control and land use decisions in the current era (Hancock, 1996). The mindset then was one of prevention rather than cure and remained an underlying feature that marked colonial town planning practices from contemporary urban planning. The drift between the two professions has become evident as they seem to be working independently or in isolation in most instances now. While several reasons continue to be adduced for the curtailment of what has largely been seen as a twinned relationship between the two professions, it is also believed that major shifts in thinking about the cause of diseases in 19th Century Europe was a major underlying cause. Miasmatic theory emerged as a dominant explanation of disease outbreaks (Maia, 2013; Sterner, 1948). Miasmas, according to Demaitre, (2004), are smells which operate through the air to enter bodies to cause diseases such as cholera. Kannadan (2018) described Miasmas as poisonous smells that polluted surrounding air to cause diseases. then became a dominant theory to explain the cause of diseases.

Miasmatic theory eventually had to give way for Germ theory which emerged as a more convincing explanation in suggesting that diseases were caused by specific agents, especially 
microbes. This new knowledge caused a further shift in thinking which eventually affected the relationship between town planning and public health (Karamanou et al. 2012). Public health professionals started to withdraw from activities designed to improve health within the built environment and channeled their energies and efforts more towards research aimed at understanding microbes and vaccines. Planners were also at this time left on their own to feel incapable and unqualified to include health considerations in their works (Arthurson, Lawless \& Hammet, 2016). This, Njoh (2012) points out, influenced post-colonial administrative practices in Africa where public health functions were differentiated from town planning. This, as would later become clearer, saw the beginning of the bifurcation of responsibilities between the two professions.

Post-colonial administrators started to put the functions of the two sectors under different ministries and it is from such a perspective that many have argued that present day urban environmental challenges in Africa are rooted in the poor performance of post-independence economic and urban planning (Adarkwa, 2012; Amoateng, Cobbinah \& Owusu-Adade, 2013). The fact modern African cities and other urbanized communities continue to experience sanitation-related disease outbreaks and on a regular basis provide ample evidence of existing weaknesses in environmental public health governance approaches. Widespread scenes of filth-laden streets, chaotic urban conditions, poverty, vulnerability, and slum settlements are reminders of failures in urban planning and management. They are symptomatic of the lack of effective urban planning and the obvious gap that exists between urban planning and public health in contemporary urban management. They also demonstrate how planning processes have failed to adhere to laid down principles of foresight analysis, proactivity, inclusiveness, equity and pro-poor considerations (Cobbinah \& Darkwah, 2016a; Watson \& Agbola, 2013).

\section{Conclusion: Minding the Gap}

Historically public health and urban planning have enjoyed an interlinked relationship that has seen the two professions grow together over time. What has come to be known as modern urban planning has its origins in the unhealthy and overcrowded industrial cities of the 19th century which raised concerns about not only the impacts of infectious disease outbreaks, but also the causes of diseases. The cause of diseases, as they became common during the industrial revolution, were ultimately attributed to poor living conditions, poor water supply, inadequate sanitation, air pollution and congestion. This realization brought urban management authorities and public health managers into strong operational relationships and in ways that have since defined the two professions as twinned.

Today, and as is common in many of Africa's large cities, we see an institutional separation of the two professions in both policy and practice and in ways that continue to negatively affect the management of urbanization processes. While several reasons have been discussed and adduced for the separation of the two professions, there is also no doubt that the realities of current urbanization processes are not entirely similar to those of the past. Historical approaches that twinned the two professions seem to have been influenced by cause and effect assumptions that followed linear analytical thinking and responses. In relative terms, such assumptions may not be valid in today's urbanization conditions as the nature and dynamics of urbanization processes have evolved and may be totally different from what happened in the past.

For most cities and other urbanizing communities, the fast-paced urbanization processes and the emergent reality of climate change and associated impacts have brought additional dimensions to the meaning and implication of public health and safety in urban communities. Urban risk management has taken on new meanings and approaches. Rising temperature, more intense and frequent precipitation have become major concerns in most cities around the world and are redefining public health and safety issues in urban communities. Inherent in the idea of urban risk management, therefore, is the emergent management requirements of resilience building and adaptation processes that seek to maintain the primacy of health, and in this regard public health and safety in urban management processes. 
To mind the gap, therefore, is to call for new and innovative approaches that consciously return the public health imperative into urban planning, but also to expand the scopes of both public health and urban planning to include emergent socio-ecological and climate changes and associated impacts on cities. Thus, beyond issues of water, sanitation, hygiene and public health, changing climatic conditions raise the propensity of other risk factors which were previously not considered or were non-issues in both in public health and built environment planning. Minding the gap, by all means, should be about maintaining the primacy of urban environmental health in urban planning processes, but should not be rigidly about reconnecting the two professions as has been the case; it should be about new perspectives and approaches to the management of health and safety in urban environments for Africa's sustainable development.

\section{References}

Adarkwa, K. K. (2012). The changing face of Ghanaian towns. African Review of Economics and Finance, 4(1), 1-29.

Aliyu, A. A., \& Amadu, L. (2017). Urbanization, cities, and health: the challenges to Nigeria-a review. Annals of African medicine, 16(4), 149.

Amoateng, P., Cobbinah, P. B., \& Owusu-Adade, K. (2013). Managing Physical Development in Peri-urban Areas of Kumasi, Ghana: A case of Abuakwa. Journal of Urban and Environmental Engineering, 7(1), 96-109.

Arthurson, K., Lawless, A., \& Hammet, K. (2016). Urban planning and health: Revitalizing the alliance. Urban Policy and Research, 34(1), 4-16.

Barros, C. P., Chivangue, A., \& Samagaio, A. (2014). Urban dynamics in Maputo, Mozambique. Cities, 36, 74-82.

Boamah, N. A. (2013). Land use controls and residential land values in the Offinso South municipality, Ghana. Land Use Policy, 33, 111-117.

Boamah, N.A., Gyimah, C. \& Nelson, J.K.B. (2012) Challenges to the enforcement of development control in the Wa Municipality. Habitat International, 36, 136-142.

Bodini, A., Bondavalli, C., \& Allesina, S. (2012). Cities as ecosystems: growth, development and implications for sustainability. Ecological Modelling, 245, 185-198.

Brooks, A. (2018). Was Africa rising? Narratives of development success and failure among the Mozambican middle class. Territory, Politics, Governance, 6(4), 447-467.

Carmichael, L., Townshend, T. G., Fischer, T. B., Lock, K., Petrokofsky, C., Sheppard, A., ... \& Ogilvie, F. (2019). Urban planning as an enabler of urban health: Challenges and good practice in England following the 2012 planning and public health reforms. Land use policy, 84, 154-162.

Cobbinah, P. B., Erdiaw-Kwasie, M. O., \& Amoateng, P. (2015). Africa's urbanisation: Implications for sustainable development. Cities, 47, 62-72.

Cobbinah, P.B. \& Erdiaw-Kwasie, M.O. (2016). Urbanisation in Ghana: insights and implications for urban governance. In: Benna, U.G., Garba, S.B. (Eds.), Population Growth and Rapid Urbanisation in the Developing World. IGI Global, United States of America, pp. 82-104.

Cobbinah, P. B., Poku-Boansi, M., \& Peprah, C. (2017). Urban environmental problems in Ghana. Environmental Development, 23, 33-46.

Corburn, J. (2004). Confronting the challenges in reconnecting urban planning and public health. American journal of public health, 94(4), 541-546.

Demaitre, L. (2004). Miasma and contagion - Epidemics in antiquity and the middle ages, Bulletin of the History of Medicine, (pp 466-468).

Duhl, L. J., Sanchez, A. K., \& World Health Organization. (1999). Healthy cities and the city planning process: $a$ background document on links between health and urban planning (No. EUR/ICP/CHDV 030403 ). Copenhagen: WHO Regional Office for Europe.

Greenberg, M., Popper, F., West, B., \& Krueckeberg, D. (1994). Linking city planning and public health in the United States. Journal of Planning Literature, 8(3), 235-239.

Hancock, T. (1996). Planning and creating healthy and sustainable cities: the challenge for the 21st century. Our cities, our future: policies and action plans for health and sustainable development, 65-88.

Hardoy, J.E., Mitlin, D., \& Satterthwaite, D. (2006) Environmental Problems in an Urbanizing World: Finding Solutions in Cities. Erathscan: London

Harrison, P. (2006). On the edge of reason: planning and urban futures in Africa. Urban Studies, 43(2), 319-335.

Henderson, J. V. (2005). Urbanization and growth. In Handbook of economic growth (Vol. 1, pp. 1543-1591). Elsevier. 
Hofmeyr, J. (2013). Africa rising? Popular dissatisfaction with economic management despite a decade of growth. Afrobarometer Policy Brief, 2.

Home, R. (2013). Of planting and planning: The making of British colonial cities. Routledge.

Hove, M., Ngwerume, E. T., \& Muchemwa, C. (2013). The urban crisis in Sub-Saharan Africa: A threat to human security and sustainable development.

Jha, A. K., Miner, T. W., \& Stanton-Geddes, Z. (Eds.). (2013). Building urban resilience: principles, tools, and practice. The World Bank.

Kannadan, A. (2018). History of the Miasma Theory of Disease.

Karamanou, M., Panayiotakopoulos, G., Tsoucalas, G., Kousoulis, A. A., \& Androutsos, G. (2012). From miasmas to germs: a historical approach to theories of infectious disease transmission. Infez Med, 2o(1), 58-62.

Karley, N. K. (2009). Flooding and Physical Planning in Urban Flooding and Physical Planning in rban areas in west Africa. A situational analysis of Accra, Ghana. Theoretical and Empirical Researches in Urban Management, Vol. 4, No. 4 (13). pp. 25-41

Keiner, M. (2004). Sustainable Development and Urban Management in Developing Countries: The case of africa. In The Real and Virtual Worlds of Spatial Planning (pp. 43-59). Springer, Berlin, Heidelberg.

Kessides, C. (1997). The urban transition in Sub-Saharan Africa: Implications for economic growth in Africa region. Lawrence, $R J$.

Konteh, F. H. (2009). Urban sanitation and health in the developing world: reminiscing the nineteenth century industrial nations. Health E place, 15(1), 69-78.

Lall, S. V., Henderson, J. V., \& Venables, A. J. (2017). Africa's cities: Opening doors to the world. The World Bank.

Maia, R. (2013). Miasma Theory of Disease. Retrieved from https://prezi.com/tiazv-ol3nqg/miasma-theory-ofdisease/

Manteaw, B. O., \& Boachie, J. (2019). Africa's urban waste management and sanitation challenges: are transfer stations the solution?

McKenzie, R.A. (2016).The Africa Rising Narrative : Whither development? Economic Discussion Papers 2016-9. Kings University, London.

Melosi, M. V., \& Hanley, J. G. (2000). The sanitary city: Urban infrastructure in America from colonial times to the present. Urban History Review, 29(1), 75.

Njoh, A. (2007). Planning power: Town planning and social control in colonial Africa. uCl Press.

Njoh, A. J. (2009). Ideology and public health elements of human settlement policies in sub-Saharan Africa. Cities, 26(1), 9-18.

Njoh, A, J. (2012). Urban Planning and Public Health in Africa

Obeng-Odoom, F. (2012). Health, wealth and poverty in developing countries: Beyond the State, market, and civil society. Health Sociology Review, 21(2), 156-164.

Okpala, D. (2009). Regional overview of the status of urban planning and planning practice in Anglophone (SubSaharan) African countries. Available on http://www. unhabitat. org/download s/docs/GRHS.

Peter, L. L., \& Yang, Y. (2019). Urban planning historical review of master plans and the way towards a sustainable city: Dar es Salaam, Tanzania. Frontiers of Architectural Research.

Porter, D. (2005). Health, civilization and the state: a history of public health from ancient to modern times. Routledge.

Roders, A. P. (2013). How can urbanization be sustainable? A reflection on the role of city resources in global sustainable development. BDC. Bollettino Del Centro Calza Bini, 13(1), 79-90.

Robinson, B., \& Swilling, M. (2012). Urban patterns for a green economy: optimizing infrastructure. United Nations Human Settlements Programme (UN-Habitat), Nairobi.

Sclar, E.D., DAch, P.G. \& Carolini, G. (2005). The 21st century health challenge of cities and slums. Millinium Project. V 365 , Issue 9462.

Saunders, D. (2011). Arrival city: How the largest migration in history is reshaping our world. Vintage.

Shen, L., Shuai, C., Jiao, L., Tan, Y., \& Song, X. (2017). Dynamic sustainability performance during urbanization process between BRICS countries. Habitat International, 6o, 19-33.

Sterner, C. S. (1948). A brief history of miasmic theory. Bulletin of the History of Medicine, 22, 747.

Storper, M. (2013). Keys to the city: How economics, institutions, social interaction, and politics shape development. Princeton University Press.

Taylor, I. (2016). Dependency redux: Why Africa is not rising. Review of African Political Economy, 43(147), 8-25.

UN-DESA. (2014). World urbanization prospects: The 2014 revision, highlights. United Nations, Department of Economic and Social Affairs (UN/DESA), Population Division. United Nations publication. Retrieved from at https://esa. un. org/unpd/wup/Publications/Files/WUP2014-Highlights.

UNEP. (2012). Principles for sustainable insurance. 
UNEP. (2013). Integrating the environment in urban planning and management. UNEP, Nairobi.

UN-Habitat. (2012). State of the World's Cities 2008/9: Harmonious Cities. Routledge.

UN-Habitat. (2014). State of the African Cities Report: Re-Imagining Sustainable Urban Transition. United Nations Human Settlements Programme: Nairobi, Kenya.

UN-Habitat. (2016) Urbanization and Development: Emerging Futures. World Cities Report 2016 (Nairobi: UNHabitat).

Verbeek, T. (2014). Reconnecting urban planning and public health: an exploration of a more adaptive approach. In Annual Congress: from control to co-evolution, Proceedings [Internet].

Watson, V., \& Agbola, B. (2013). Counterpoints: Who Will Plan African Cities. African Research Institute.

Yankson, P. W., \& Bertrand, M. (2012). Challenges of urbanization in Ghana. The Mobile City of Accra, 25. 